\title{
Simulation Analysis of Hypertension Patients' Pulse Waveform Based on Cardiovascular Electrical Network Model
}

\author{
Liangyu $\mathrm{He}^{1}$, Jianjun Yan ${ }^{1,{ }^{* a}}$, Haixia Yan ${ }^{2}$, Rui Guo², Guoping $\mathrm{Liu}^{2}$, Yiqin \\ Wang ${ }^{2, * b}$ \\ ${ }^{1}$ School of Mechanical and Power Engineering, East China University of Science and Technology, \\ Shanghai 200237, China. \\ ${ }^{2}$ Laboratory of Information Access and Synthesis of TCM Four Diagnosis, University of Traditional \\ Chinese Medicine, Shanghai 201203, China

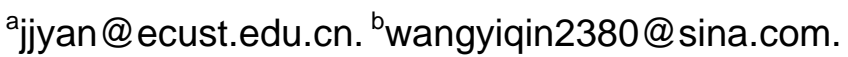

Corresponding authors: Jianjun Yan, jjyan@ecust.edu.cn; Yiqin Wang, wangyiqin2380@sina.com

Keywords: Cardiovascular electrical network model; pulse waveform; hypertension; Objectivity of TCM.

Abstract. As an important part of traditional Chinese medicine (TCM), the pulse taking is the profound essence of TCM. The electrical network model of cardiovascular system coupled with a 10-unit and left-arm simplified model was established using SimPowerSystem components of Matlab based on the previous researches, to analyze the correlation between the pulse wave and human cardiovascular physiological and pathological. By adjusting the hemodynamic parameters of the model, the pulse waveform of different pathological period at the radial artery in hypertensive patients was outputted, thus establishing a certain foundation for objectifying pulse taking and providing with some reference value.

\section{Introduction}

During the analysis of pulse taking of TCM, an intuitive time-domain analysis method [1] is used to find inherent connections between some characteristics and changes in pulse taking through the parameter analysis of the height and area values of main wave and dicrotic wave [2,3]. However, these characteristic amounts estimated on the basis of experiences are difficult to obtain, and the random errors are comparatively large. Using the frequency domain analysis [4] with fast discrete Fourier transform, the pulse wave in the time domain can be converted to the frequency domain, to extract relevant physiological and pathological information by analyzing the features of frequency spectrum curves obtained. The conjoint analysis of time-frequency domain [5,6] can transform the one-dimensional signals into a two-dimensional function of time and frequency, and the time-frequency plane can describe the frequency spectrum at each moment. However, these methods can not solve the issue of objectifying pulse-taking of TCM in depth. Based on the classic double elastic cavity model, the hybrid electrical network model coupled with 15-unit model and left arm refined model is simplified in this study [7], by establishing the electrical network model of cardiovascular system of 10-unit coupled with left arm simplified model in human and adjusting the model parameters, the pulse waveform of different pathological period at the radial artery in hypertensive patients can be outputted, thus promoting the study on objectifying pulse-taking of TCM by establishment the correlation between the sphygmogram and hemodynamic parameters from the internal mechanism of the cardiovascular system.

1. Establishment of the cardiovascular system electrical network model coupled with a 10-unit and left arm simplified model

\subsection{Cardiac excitation source model}


Cardiac excitation source model [8] is established based on the real internal physiological structure of the human heart. This model includes mainly the left ventricle, left atrium, mitral and aortic valve, and the pulmonary circulation of five parts. According to the equivalent relationship between fluid networks and electrical circuit, the use of the Kirchhoff's law of voltage and current node can describe the coupling relationship among each branch of the blood circulation. In order to achieve the solution of this cardiac excitation source model, the equivalent circuit model is required to be converted into the form of a mathematical model, shown as the following formula:

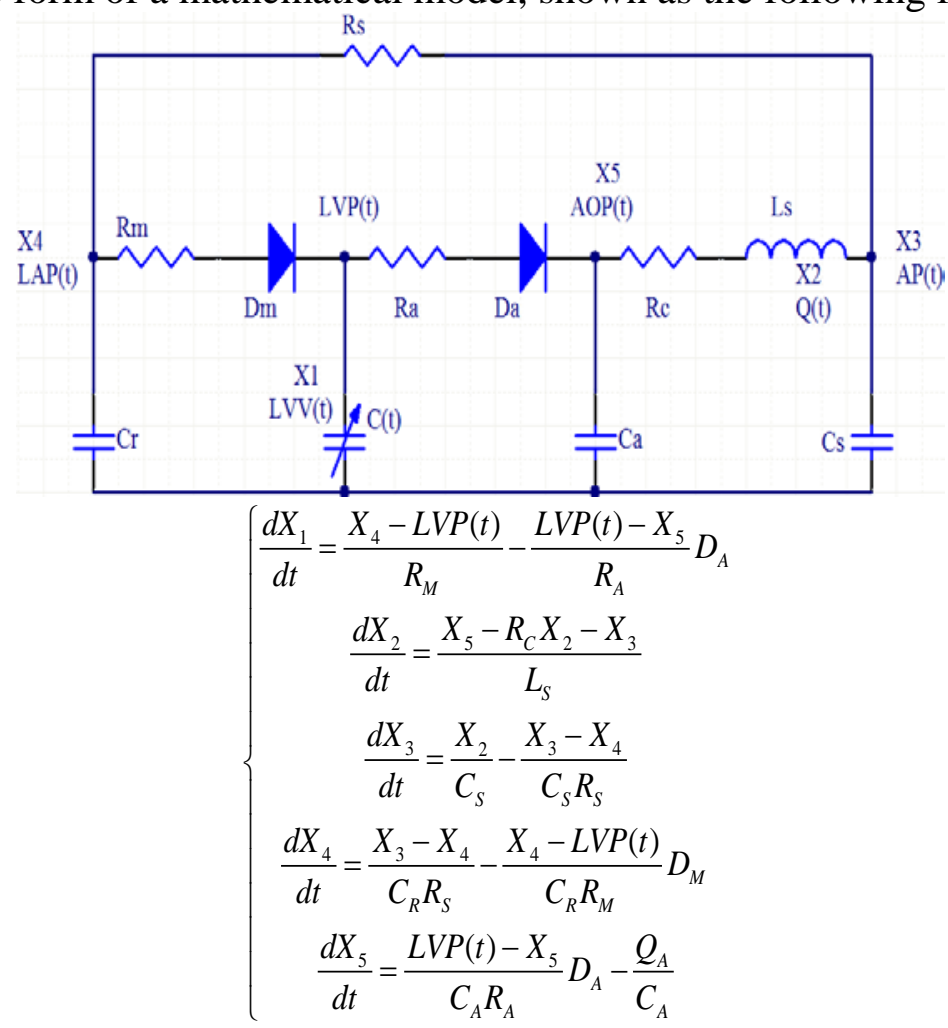

Fig. 1 Cardiac excitation source equivalent circuit and mathematical model

Where, $D_{m}, D_{a}$ is 0 or 1 variable, which represents respectively the open or closed state of mitral and aortic valves, the conditional expression for judging open or closed state is as follows:

$$
D_{m}=\left\{\begin{array}{l}
1, \text { if }\left(\left(X_{4}-L V P(t)\right)>0\right. \\
0, \text { if }\left(\left(X_{4}-L V P(t)\right) \leq 0\right.
\end{array} \quad ; \quad D_{a}=\left\{\begin{array}{l}
1, \text { if }\left(\left(L V P(t)-X_{5}\right)>0\right. \\
0, \text { if }\left(\left(L V P(t)-X_{5}\right) \leq 0\right.
\end{array}\right.\right.
$$

Table 1 State variables of cardiac excitation source model

\begin{tabular}{c|c|c|c|c|c}
\hline Variable & $X_{1}(t)$ & $X_{2}(t)$ & $X_{3}(t)$ & $X_{4}(t)$ & $X_{5}(t)$ \\
\hline Symbol & $L V V(t)$ & $Q(t)$ & $A P(t)$ & $\operatorname{LAP}(t)$ & $A O P(t)$ \\
\hline $\begin{array}{c}\text { Physiological } \\
\text { implications }\end{array}$ & $\begin{array}{c}\text { Left ventricular } \\
\text { volume }\end{array}$ & $\begin{array}{c}\text { Aortic } \\
\text { blood flow }\end{array}$ & $\begin{array}{c}\text { System arterial } \\
\text { pressure }\end{array}$ & $\begin{array}{c}\text { Left atrial } \\
\text { pressure }\end{array}$ & Aortic pressure \\
\hline
\end{tabular}

\subsection{Cardiovascular system electrical network model coupled with a 10-unit and left arm simplified model}

In establishing the cardiovascular system electrical network model, based on the fluid network theory [9], the analog relationship between the hemodynamic parameters and electrical constants is established, including that the capacitance $\mathrm{C}$ represents the arterial compliance; inductance $\mathrm{L}$ represents the blood flow inertia; electric resistance $\mathrm{R}$ represents the blood viscous resistance. The analog relationship between the hemodynamic parameters and electrical quantities is shown in Table 2:

Table 1 Hemodynamic parameters analogical relationship with electrical quantities

\begin{tabular}{c|c|c|c}
\hline Name & $\begin{array}{c}\text { Viscosity resistance } \\
\mathrm{R}(\mathrm{mmHg} \mathrm{s} / \mathrm{mL})\end{array}$ & $\begin{array}{c}\text { Arterial compliance } \\
\mathrm{C}(\mathrm{mL} / \mathrm{mmHg})\end{array}$ & $\begin{array}{c}\text { Blood flow inertia } \\
\mathrm{L}(\mathrm{mmHg} \mathrm{s} \wedge / \mathrm{mL})\end{array}$ \\
\hline Analogy objects & Resistance & Capacitance & Inductance \\
\hline
\end{tabular}


Formulas

$$
\begin{array}{c|c|c}
R=\frac{128 \mu l}{\pi D^{4}} & \mathrm{C}=\frac{\pi D^{3} l}{4 E h} & L=\frac{4 \rho l}{\pi D^{2}}
\end{array}
$$

Where $\mu$ is the blood viscosity, $l$ is the length of the artery segment, $\mathrm{D}$ is the diameter of the artery segment, $\mathrm{E}$ is Young's modulus, $\mathrm{h}$ is the thickness of the blood vessel wall.

In this paper, the SimPowerSystem component of Matlab was used to establish a cardiovascular system electrical network model coupled with a 10-unit and left arm simplified model using the output of cardiac excitation source model as the input source.

Human arm consists of seven segments of artery, including the subclavian artery I, vertebral artery, subclavian artery II, radial artery, ulnar artery I, interosseous artery, ulnar artery II. In order to increase computing speed and efficiency, the interosseous artery, ulnar artery II and ulnar artery I were combined for processing. Five units of left arm simplified model was shown in Table 3.

Table 3 Unit name of left arm simplified model

\begin{tabular}{c|c|c|c|c|c}
\hline Name & Arm_1 & Arm_2 & Arm_3 & Arm_4 & Arm_567 \\
\hline $\begin{array}{c}\text { Artery } \\
\text { segment }\end{array}$ & $\begin{array}{c}\text { Subclavian artery } \\
\text { I }\end{array}$ & $\begin{array}{c}\text { Vertebral } \\
\text { artery }\end{array}$ & $\begin{array}{c}\text { Subclavian } \\
\text { artery II }\end{array}$ & Radial artery & $\begin{array}{c}\text { Left ulnar artery, left } \\
\text { interosseous artery, left ulnar } \\
\text { artery II }\end{array}$ \\
\hline
\end{tabular}

The 10-unit lumped model for systemic cardiovascular system consists of the ascending aorta, brachiocephalic artery, upper extremity circulation, upper vena cava, thoracic aorta, abdominal aorta, renal circulation, visceral circulation, lower extremity circulation, abdominal vena cava, thoracic vena cava 11 sections. As the venous circulation has a small effect on the pulse waveform, the lumped parameterization treatment was performed. The 10 units of a 10 -unit lumped model were shown in Table 4.

Table 4 Unit name of 10-unit lumped model

\begin{tabular}{c|c|c|c|c|c}
\hline Name & Cell_1 & Cell_2 & Cell_3 & Cell_4 & Cell_5 \\
\hline $\begin{array}{c}\text { Artery } \\
\text { segment }\end{array}$ & $\begin{array}{c}\text { Ascending } \\
\text { aorta }\end{array}$ & $\begin{array}{c}\text { Brachioceph } \\
\text { alic artery }\end{array}$ & $\begin{array}{c}\text { Circulation of } \\
\text { upper extremity }\end{array}$ & $\begin{array}{c}\text { Veins of upper } \\
\text { extremity } \\
\text { Circulation of Cava }\end{array}$ & Thoracic aorta \\
\hline Name & Cell_6 & Cell_7 & Cell_8 & Cell_9 & Cell_10 \\
\hline $\begin{array}{c}\text { Artery } \\
\text { segment }\end{array}$ & $\begin{array}{c}\text { Abdominal } \\
\text { aorta }\end{array}$ & $\begin{array}{c}\text { Renal } \\
\text { circulation }\end{array}$ & $\begin{array}{c}\text { Visceral } \\
\text { circulation }\end{array}$ & $\begin{array}{c}\text { Circulation of lower } \\
\text { extremity }\end{array}$ & $\begin{array}{c}\text { Abdominal vena cava } \\
\text { and thoracic vena cava }\end{array}$ \\
\hline
\end{tabular}

The following figure shows the cardiovascular system electrical network model coupled with a 10-unit and left arm simplified model.

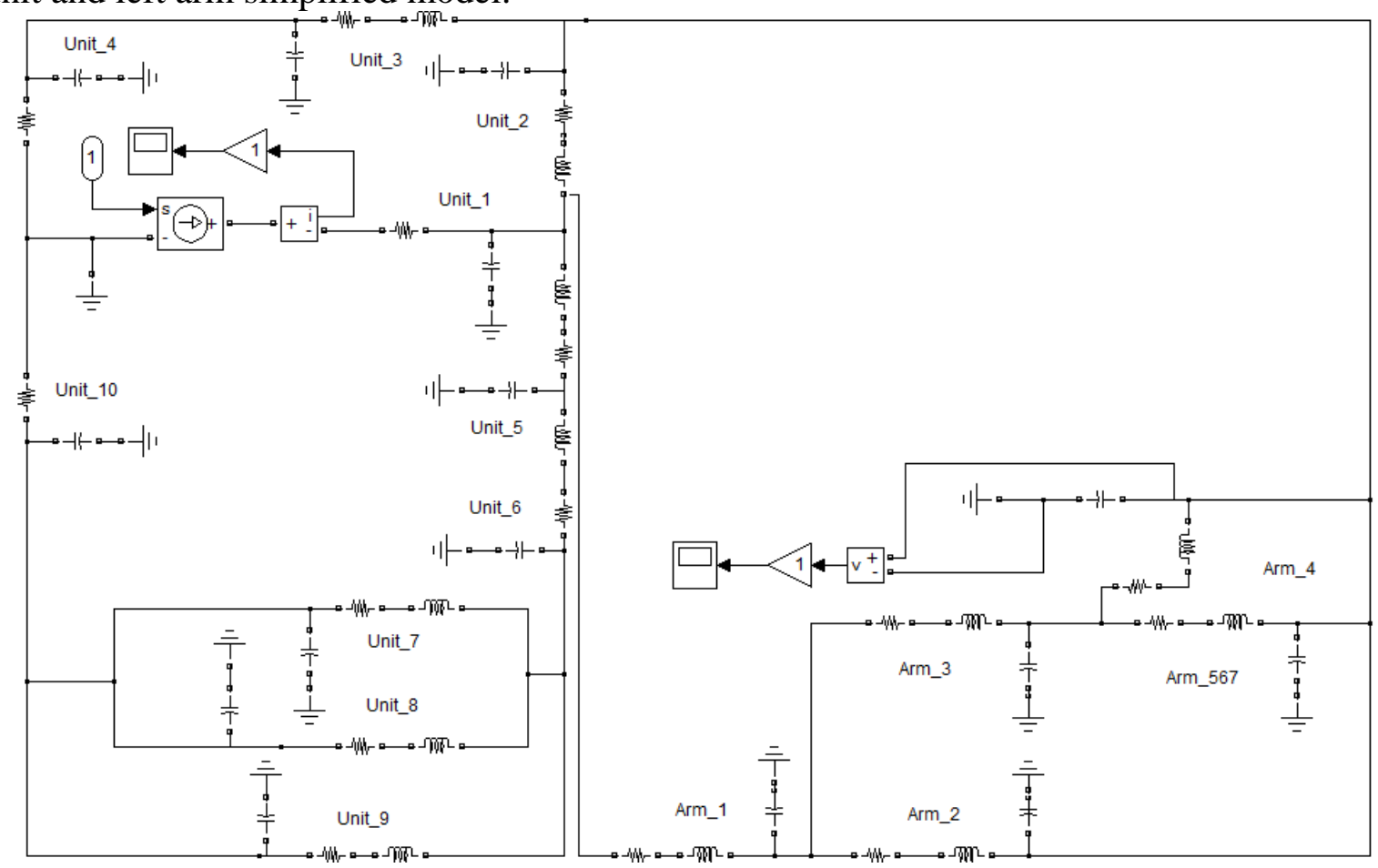

Fig. 2 Cardiovascular system electrical network model coupled with a 10-unit and left arm simplified 
model

\section{Phantom analysis of pulse waveform in hypertensive patients based on the whole cardiovascular electrical network model}

Hypertension is a syndrome with a series of clinical symptoms and a continued increase of systemic circulation arterial pressure as the mainly manifestation. The World Health Organization (WHO) states: systolic blood pressure greater than $140 \mathrm{mmHg}$, diastolic blood pressure greater than $90 \mathrm{mmHg}$, can be identified as hypertension. Wire pulse is the main pulse type of hypertensive patients. The pulse of hypertensive patients in early and middle stage is mostly bimodal or simple wire pulse, while the majority of advanced patients are oblique peak wire pulse.

Table 5 Hemodynamic parameter values of three wire pulses

\begin{tabular}{c|c|c|c|c|c|c|c|c|c}
\hline Name & \multicolumn{3}{|c|}{ Pure Wiry pulse } & \multicolumn{3}{c|}{ Bimodal Wiry pulse } & \multicolumn{3}{c}{ Oblique peak Wiry pulse } \\
\hline variable & $\mathrm{R}$ & $\mathrm{C}$ & $\mathrm{L}$ & $\mathrm{R}$ & $\mathrm{C}$ & $\mathrm{L}$ & $\mathrm{R}$ & $\mathrm{C}$ & $\mathrm{L}$ \\
\hline Arm_1 & 0.01568 & 0.00132 & 0.00737 & 0.00177 & 0.00440 & 0.00624 & 0.04260 & 0.00128 & 0.00642 \\
\hline Arm_2 & 1.07870 & 0.00937 & 0.09672 & 0.18489 & 0.00969 & 0.05115 & 1.76727 & 0.00298 & 0.17739 \\
\hline Arm_3 & 0.22769 & 0.41353 & 0.07729 & 0.05987 & 0.33451 & 0.02953 & 0.22771 & 0.06584 & 0.09358 \\
\hline Arm_4 & 0.48865 & 0.06293 & 0.06237 & 0.04165 & 0.05243 & 0.03352 & 0.52850 & 0.03509 & 0.10557 \\
\hline Arm_567 & 0.22954 & 0.03560 & 0.01237 & 0.2294 & 0.06290 & 0.01510 & 0.23205 & 0.02256 & 0.01648 \\
\hline Cell_1 & 0.00601 & 0.22197 & & 0.00066 & 0.36774 & & 0.01281 & 0.29812 & \\
\hline Cell_2 & 0.00367 & 0.19928 & 0.00129 & 0.00084 & 0.19387 & 0.00253 & 0.00494 & 0.18365 & 0.00193 \\
\hline Cell_3 & 0.02157 & 0.59379 & 0.17927 & 0.2145 & 0.3256 & 0.16939 & 0.30805 & 0.24201 & 0.17183 \\
\hline Cell_4 & 0.05138 & 1.5956 & & 0.04933 & 2.0861 & & 0.06758 & 1.5424 & \\
\hline Cell_5 & 0.00660 & 0.28111 & 0.00054 & 0.01633 & 0.28818 & 0.00082 & 0.02553 & 0.24177 & 0.00083 \\
\hline Cell_6 & 0.01616 & 0.17840 & 0.01166 & 0.00178 & 0.17183 & 0.00037 & 0.01948 & 0.12812 & 0.00150 \\
\hline Cell_7 & 0.42754 & 0.28895 & 0.01308 & 0.39776 & 0.27067 & 0.01306 & 0.4558 & 0.24729 & 0.00395 \\
\hline Cell_8 & 0.34154 & 0.30332 & 0.00536 & 0.35596 & 0.6789 & 0.00388 & 0.36655 & 0.22822 & 0.04732 \\
\hline Cell_9 & 0.03847 & 0.6647 & 0.44093 & 0.37168 & 0.82403 & 0.40456 & 0.04847 & 0.62083 & 0.40712 \\
\hline Cell_10 & 0.04285 & 0.34705 & & 0.05013 & 0.49335 & & 0.05635 & 0.30113 & \\
\hline
\end{tabular}

The hemodynamic parameters of blood vessels in early hypertensive patients were close to normal; the peripheral resistance of blood vessels of mid-term hypertensive patients was high, but the arterial compliance was small; the late hypertension will be accompanied by a variety of complications, the peripheral resistance of blood vessels will further increase, while the arterial compliance will decrease.

The parameters values for each variable within a given range were adjusted based on the characteristics of hemodynamic parameters at different stages of hypertension, as shown in Table 5. At the radial artery unit, the phantom output of pressure waveform of pulse waveform pattern corresponding with the simple, bimodal and oblique peak wire pulse in hypertensive patients of different periods were performed, the specific waveform were shown in Fig. 3. 


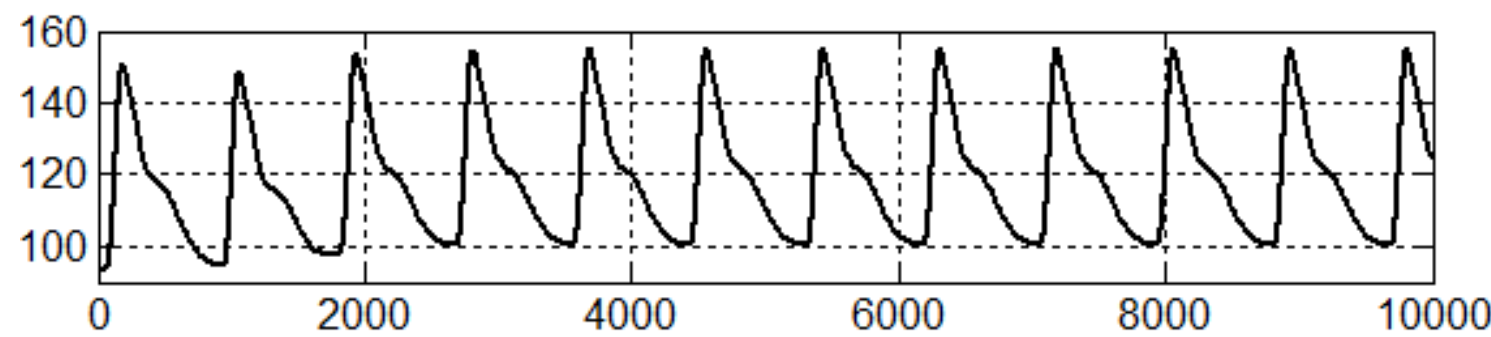

(a)

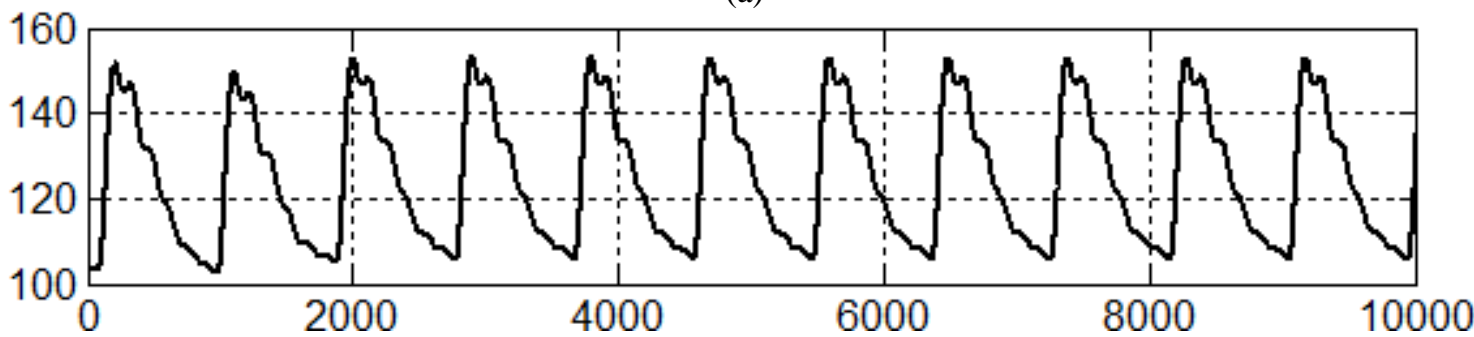

(b)

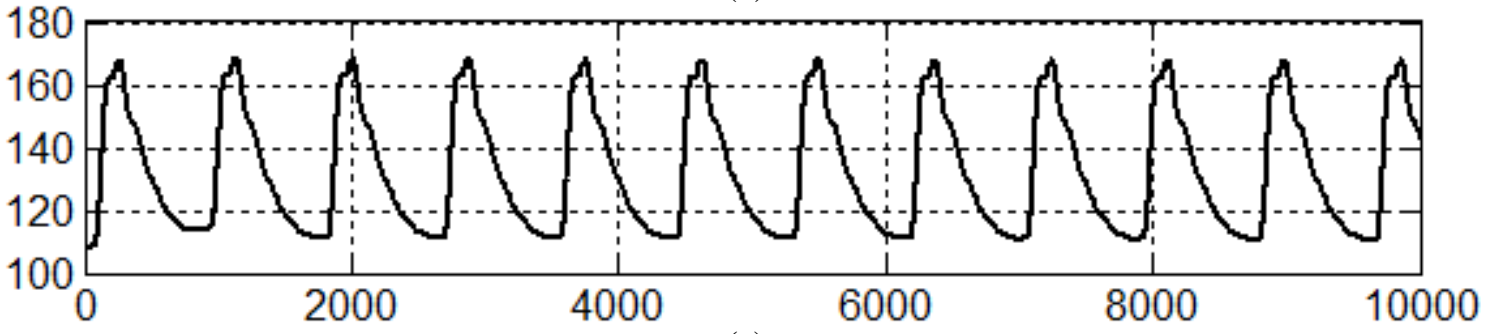

(c)

Fig. 3 Phantom output of pulse waveform of hypertensive patients

(a. Simple wire pulse; b. Bimodal wire pulse; C. Oblique peak wire pulse)

\section{Summary}

In this paper, the SimPowerSystem component of Matlab was used to establish the cardiovascular system electrical network model coupled with the 10-unit and the left arm simplified model for phantom to obtain the pulse waveform of hypertensive patients with different periods, which can be used to analyze the relationship between the pulse waveform and the hemodynamic parameters changes to provide a new idea for objectifying pulse taking of TCM.

\section{Acknowledgment}

This work was supported by National Natural Science Foundation of China for Youth under Grant No. 81302913 \& No.81102729, National Natural Science Foundation of China under Grant No. 81173199, 81270050, 30901897, 81173199 and 30701072

\section{References}

[1] O’Rourke MF, Pauca A, Jiang XJ. Pulse wave analysis [J]. Br J Clin Pharmacol. 2001; 51(6): 507-522.

[2] Luo ZC, Yang ZB. A study on the information of pulse wave characteristics [J]. BeijingGong Y e Da Xue Xue Bao. 1996; 22(1): 71-79.

[3] Chun T Lee, Ling Y Wei. Spectrum analysis of human pulse [J]. IEEE Tran. On BME. 1983, 30: 348-352.

[4] C T Lee, et a1. Frequency distribution of human pulse spectra [J]. IEEE Trans.Biomed Eng. 198 5, Vol BME, 32: 254-249.

[5] Leonard P, Beattie TF, Addison PS, Watson JN. Wavelet analysis of pulse oximeter waveform permits identification of unwell children [J]. Journal of Emergency Medicine. 2004, 21: 59 - 60. 
[6] Zhang D, Zhang L, Zhang D, Zheng Y. Wavelet based analysis of Doppler ultrasonic wrist-pulse signals [C]. In: Proceedings of the ICBBE 2008 conference. 2008, 2: 539-543.

[7] T Heldt, R Mukkamala, GB Moody, and RG Mark.CVSim: An Open-Source Cardiovascular Si mulator for Teaching and Research [J]. Open Pacing, Electrophysiol\&Thery, 3: 45-54 (2010).

[8] Hu Zhe, Diao Ying - min. Primary model of heart-systemic pulmonary system [J]. Journalof Ton gji University. 2002, 30(1): 61-65.

[9] M.X.Li, J.J.Beech-Brandt, L.R.John . Numerical analysis of pulsatile blood flow and vesselwall mechanics in different degrees of stenoses $[\mathrm{J}]$. Journal of Biomechanics, $2007, \quad 40$ : 3715-3724. 